\title{
The Swedish Elderly and Psychiatric Healthcare as Models: An Investigation into the Social Importance of Healthcare and Biomedical Science Research
}

\author{
Desmond Ayim-Aboagye* \\ Department of Human Development and Psychology, Regent University College of Science and Technology Ghana
}

*Corresponding author: Desmond Ayim-Aboagye, Department of Human Development and Psychology, Regent University College of Science and Technology Ghana.

To Cite This Article: Desmond Ayim-Aboagye. The Swedish Elderly and Psychiatric Healthcare as Models: An Investigation into the Social Importance of Healthcare and Biomedical Science Research. Am J Biomed Sci \& Res. 2021 - 14(1). AJBSR.MS.ID.001944.

DOI: 10.34297/AJBSR.2021.14.001944.

Received: 盋 August 11, 2021; Published: 眥 August 26, 2021

\begin{abstract}
Aim

Sweden continues to enjoy the elderly and psychiatric healthcare in its welfare state. This development could not have been successful without the hard work of biomedical scientists and their researchers. We investigate in this study the involvement of biomedical research, its personnel and the way it has championed new knowledge and confidence in the industries as a whole. Moreover, the psychiatric work in prison institutions is investigated to find out how inmates are being helped by these professionals to deal with their guilt.
\end{abstract}

\section{Methodology}

The methodology I employed allowed me to combine interviewing and hypothesis testing to gain a deep knowledge of the healthcare industry. The statistical analyses employed were Analysis of Variance (ANOVA) and Regression analysis. The SPSS aided me in dealing with the study's aim. ANOVA as an omnibus allowed me to work with causal relationships between several variables. Regression is a powerful tool for summarizing the nature of the relationship between variables and for making predictions of likely values of the dependent variable.

\section{Results}

The Swedish welfare system is tremendously dependent on the ideas of the biomedical professionals that function as curers and managers in managing these industries. They also conduct successful research to look for appropriate manners where patients could receive maximum care. Biomedical research, its personnel, and the way it has championed new knowledge and confidence in the industries as a whole are indispensable. They are the CEOs who manage the healthcare industries and organize conferences that look for progress on the way. The Social Steering Board (Social Styrelsen) comprises men who possess enormous political experiences and biomedical scientists who have extensive knowledge in research. They carry out programs that steer and manage the welfare programs in the Elderly and the Psychiatric Wards. In two multiple regression analyses used in the study, deeply felt positive mood and usefulness of the chaplain's work were significantly and positively associated with changes in attitudes and behavior. Only church attendance was negatively significant with changes in attitudes and behavior. This finding is of interest because the government and the church spend money to enable the prison chaplains to function better in prisons. These findings will support the fact that the chaplains' work must go on among the outside communities, but also the inmates.

\section{Conclusion}

Biomedical research, its personnel, and the way it has championed new knowledge and confidence in the industries as a whole should be rewarded. The work of the CEOs who manage the healthcare industries and organize conferences that look for progress on the way must be investigated. Research on the Social Steering Board (Social Styrelsen), which comprises men and women who possess enormous political experiences and biomedical scientists who have extensive knowledge in research should be prioritized. The present study also indicates that the chaplains' work associates with attitudes and behavioral change that immigrant inmates experience in prison. The two predictive factors, the usefulness of the chaplain's work and deeply felt positive mood tell us that the work of the careers in prison is significant not only to the public healthcare but also to the inmates coping strategy.

Keywords: ANOVA: Analysis of Variance; BBC: The Global Age Watch Index; CSW: Commission for Angling Welfare; CSW: Commission for Angling Welfare 


\section{Introduction}

The Elderly healthcare system and the Psychiatric healthcare in Sweden have one of the most advanced models that any developed or developing nation could emulate. At a glance, the novice may not discover the strategic development behind this care which caters to the seniors in society. The meticulous thinker would observe that this care of the seniors and the psychiatric care of prisoners are not only important industries by themselves but also are stupendous backbones of the welfare state. Sweden nation has been a welfare state for more than five decades ago. This development could not have been successful without the contribution of biomedical science and research. We will investigate in this study the involvement of biomedical research, its personnel, and the way it has championed new knowledge and confidence in the industries as a whole.

\section{The Objective of the Study}

The purpose of the article is to study the conditions which make the care of the elderly industry grow and also suggest its emulation by the developing nations. We shall also find how the development of biomedical science, its personnel and research has generated the continued progress in healthcare. The study will contribute to the analysis of data that shows there is progress in the Prison Institution's welfare program. These empirical materials will reveal rigorous analysis through thorough investigations.

\section{Research Questions}

a) How do the elderly and psychiatric healthcare in Sweden function?

b) Could the Chaplains/Carers work in the Prisons Institutions influence the inmate's attitudes and behaviors?

c) Could the deeply felt mood the inmates possess, as a result, of the chaplain's work and their constant church attendance practices, influence the attitudes and behaviors of inmates in the Prison Institutions?

\section{Main Hypotheses}

The Carers' work will have a positive effect on the inmate's attitudes and behaviors.

The inmates' deeply felt positive mood and their church attendance practices will have a positive effect on the inmates attitudes and behaviors.

\section{Background Data and the Importance of the Study}

Elderly care consists of one of the universal and comprehensive social and health care programs in Sweden. The taxes of the citizens fund the care system. Sweden allocates 3.6\% of its GDP on longterm care and gives the highest healthcare employees for the elderly over 65 years. In 2013, Sweden became the first among the countries that provide superb care to its elderly. The United
Nations-supported global study and The Global Age Watch Index (BBC) made this information available. The nation constantly institutionalizes reforms that are high-quality long-term care for the elderly institutions and home care. The municipalities take responsibility for elderly care and issue funds for home assistance. It also controls the prerequisite of available housing. Currently, 94\% of the elderly over 65 years are living in their homes. These seniors live independent lives and still receive their home assistance. If an elderly require assistance from a healthcare worker, she could apply and get it. There are cooked meals which the elderly could request for them, and she will get them. One behavioral characteristic which concerns every Swede is independence. Caretaking of the elderly adapts to this common characteristic. The caretaking of the elderly in their homes allows them to enjoy this independence. It consoles family members to have their peace of mind knowing that their loved ones will receive superb care and love from professionals. In addition to this, the seniors could choose to stay at home or join a nearby care company where several elderly persons live. The care where the elderly receives their choices comes from the fact that the elderly has contributed to the various communities where they once lived. They have worked day and night, raised their families, and paid their taxes, according to the laws of the nation. As written by Martina Lesperance, "they deserve to receive the same high quality of care. In addition to the care the elderly receive, health care workers are needed and appreciated. So, it is a win-win situation for everybody: the elderly, their families, as well as all current and futures citizens of Sweden [1].

\section{Healthcare and Biomedical Science Contribution}

The Swedish elderly care as an institution continues to receive modernization and development. But the major contribution comes from biomedical science, its personnel, and research, which championed new knowledge that the different commissions that the state instituted utilized to make changes. Science research has helped the care industry to be modernized to incorporate several health models. This enhanced the single purpose of allowing people to enjoy their independence without infringing on the quality aim enshrined in the core objectives.

High life expectancy buttressed by Continuous Care and investigations by Biomedical Doctors: Life expectancy in Sweden is among the highest in the world. Men have 80.6 years, while women have 84.29 years. The country can boast about 5 percent of its population, which are above 80 years or older. Here, not only research but also there is constant consultation with experts in the care field to check patients regularly about their health status.

Largely Funded by Taxes: Social Service Act controls the care of the elderly, and this Act gives the municipalities the power to steer the industry. Municipal taxes and government grants govern the industry. Statistics have it that in 2018 the cost of elderly care came 
to be 126.3 billion Swedish Kronors. The municipalities subsidized any health care costs incurred by the elderly. The laws even allow a couple who have lived together for an extended period to continue living. They shall receive support. When new research appears in a biomedical science journal that challenges certain principles in this Act, they will change it.

Public and Private: Currently, Private Companies are joining hands with the municipalities to cater to the care of the elderly even though the Municipalities continue to have the sole responsibility as an organ. These private companies consist of experts in the biomedical science fields. They recruit their CEOs from the same biomedical disciplines.

Accessible Housing: Houses in the country must meet the needs of the elderly and those with disabilities. These accessibility requirements have been given greater prominence in legislation over the years. There are specific homes for "senior homes," where people over 55 years and above stay.

Home Help Makes Life Easier with Assistance from Different Health Professionals: The elderly and those with disabilities must enjoy their independent lives and, this extends to their homes. There are already-cooked meals and various kinds of help which facilitate and make life easier. In 2020, around 236000 people over 65 years worked as assisted health care professionals. The employees include doctors, nurses, dieticians, physiotherapists, etc.

Individual Assessed Assistance by Biomedical Doctors: The extent of care needed by an elderly person is always subject to assessment and this must be initiated by the individual through the application to the municipalities. Those elderly persons with disabilities are capable of receiving help quicker because they give them special preference. The same applies to those who are severely sick and demand constant and meticulous care. Biomedical doctors and other health care professionals such as nurses assist them.

Transportation Services: Those elderly who are weak and could not travel by ordinary transport and those with disabilities could have special assistance. They travel by special cars and buses which are adapted for them to use. Again, biomedical scientists dominate in research into these areas.

Physical activity on Prescription by Biomedical Doctors and Nurses: Preventive health care is also becoming popular in Sweden. It has been possible through new research advanced in biomedical science. Because of its aging population, now biomedical doctors can prescribe physical activity with or without drugs to enable the elderly to obey the health principles. Already in their restaurants and cafeterias, some dieticians manage the type of food these seniors regularly eat.

Stimulation Through Arts Works Through Prescriptions by Biomedical Doctors: Apart from minor injuries which occur to them while changing bulbs in their rooms or cleaning, there are no dangers to the seniors. They receive stimulation through listening to music, reading books, painting, different cultural activities and sports [2, 2.1-2.5].

\section{The Welfare/Healthcare in Prisons}

The Commission for Angling Welfare (CSW) abbreviated in Swedish as NAV (i.e., Nämnd för Andlig Vård) is responsible for the health care of prisoners. These consist of one hundred and ten detentions and prisons spread all over Sweden. The responsibility for the CSW concerns that of existential questions, ethics, and religion in Swedish prisons. One cardinal purpose for this responsibility is to guard against the fundamental law regarding freedom of worship. Even those who are deprived of movement are entitled to enjoy it. The CSW presence, therefore, ensures the possibility that all prisoners will keep whatever forms of religion they wish to adhere to. By the request of a prisoner, a pastor could therefore engage in individual psychological counseling and attend to the inmates' confessions under the general protection law of the Oath of silence (tystnadsplikt). Through this, inmates get support, which enables them to adjust to their personal and existential problems. Furthermore, inmates participate in church services and prayer meetings to have sacraments and other religious practices in the prisons. The CSW organ seeks permission from the appropriate authorities for those inmates who are interested to freely participate [3].

\section{Health Care in Detentions and Prisons are managed by Carers and Biomedical Science Professionals}

Three eminent people help in executing the functions of the CSW. They are the chief of the board of CSW, a priest from the Church of Sweden, and a pastor elected from the Free Churches in Sweden. The board of all the Dioceses chooses a priest who is also responsible for financing all activities. The Free Churches pastors take all responsibilities regarding the services of the Free Church Council of Sweden. The Board of Prison's Director knows these men. The National Prisons pays salaries to the Free Church pastors working as chaplains in the prisons. When needs arise, priests from other denominations such as the Catholic church, Orthodox churches, or Islamic organizations can work as adjunct pastors with funds from the National Prisons. The CSW performs the function of representing their respective denominations or churches. The CSW also decides on the activities, which take place in the prisons and detentions. The CSW holds 1-3 meetings in a semester (6 months) with delegates comprising representatives of the inmates and those staff who work with prison activities. These include the recreation leader and one person who is responsible for treatment programs. Christian Visitation Groups present a delegate during the CSW meetings. The CSW is responsible to the inmates about their entitlement to health care/welfare and other activities. 
The CSW continually discusses its area of responsibility and takes up and analyses the previous meetings.

Detentions: The task of the members of the CSW is to organize a private conversation with inmates. Where certain restrictions are placed on inmates, pastors, with the help of some staff are allowed to visit inmates in their cells. Inmates decide whether or not they will be willing to have a priest come in and converse with them. Those in detention are by law not guilty but for security reasons must be in detention until the day of their trial. Most inmates, therefore, find it difficult because the longer the period they stay, the more they may develop existential crisis and fear. Not only them, but also members of the family become worried. The lesser outside contacts mean that they cherish every bit of personal conversation with the pastor. It is the time to adapt to change concerning their whole life situation. Moreover, isolation causes an inmate to take some decisions whose consequences could not be determined. Health care constitutes active listening, careful adaptation, and spiritual direction to allow inmates to gain courage and self-esteem. Inmates can participate in group conversations and other arranged programs organized by the members of CSW.

Prisons: Inmates in prison institutions participate in social gatherings within a relatively closed system. They can take part in daily works, studies, treatment programs, and leisure games which are healthcare prescriptions by biomedical doctors. Dissension and conflicts can ensure occasionally, but these cannot overshadow the positive moods often experienced by most inmates. The CSW pastor's task is to visit regularly the environment where these things are taking place. A pastor feels the life of the prison community. He makes contact among both the inmates and the staff better. The assumption is that, by so doing, a pastor can engage in a conversation in these different environments to lessen the unhealthy talks that often breed abuse and criminality, and instead, provide alternative values. Inmates who wish to book an appointment for private conversation do so on these occasions. The pastors propose a beneficial activity to those within and outside the prisons through consultation with the staff and inmates. The individual comes to gain support through personal dialogue and gains both psychological and psychical development. The care in prison institutions aims at working with the inmates and giving them strong psychological motivations and support for them to regain their self-esteem. It is carried out through personal contacts, psychological and counseling support, and spiritual direction guided by Christian ethics. The common principles guiding their work are that first, all persons are equal in value and worthy of respect irrespective of their actions. Secondly, that every person has his/her resources which can be developed positively [4]. The CSW pastor's and priests' work schedule contains the following:

a) Consult individual inmates for psychological and counseling sessions. b) Organize programs and activities for the inmates.

c) Lead in-group visitation activities.

d) Organise church services, prayer meetings, and communion services.

e) Perform or officiate confirmation, marriages, and burial services.

f) Lead conversation groups and study circles.

g) Supply Bibles, songbooks, and other Christian literature.

h) Give information about work in the outside congregations to the prisoners.

i) Participate in the introduction of new inmates.

j) Assist in the different treatment programs.

Participate in the staff meetings and the staff education programs.

Act as a mediator between representatives of other churches/ congregations and [5]. The CSW pastors cooperate with the families of the inmates. Their activities correspond to the ecumenical aim of cooperating with different churches and other organizational networks in Sweden.

\section{Theoretical Framework}

\section{Swedish Healthcare has Relationships in Focus}

In this theoretical perspective, I have chosen to discuss care in relationships as I believe strongly that Swedish healthcare focuses on family and relationships. In any healthcare also special attention is given to the family. This care focuses on human relationality and the issue of how a person can be fully relational without losing his/ her individuality. The relationship concerns special relationships of human life, most often those of kinship, but sometimes relationships of friendship. The theory of care given in counseling psychology involves individuals in dealing with two fundamental balances of care. They are (1) care for themselves as individuals and care for the relationships that are most important to them; and (2) a balance of care among the generations close to them, that is, their generation, the generation before, and the generation that comes after them. When it comes to human relationships, difficulties are encountered, as it is not easy to find the message that the care model offers for the practitioner of care of the family. Because what the Judeo-Christian tradition asserts about the special relationships of the family is bound to an ancient culture, it makes it difficult for the acceptance of its authority by some literal interpreters. The Christian tradition indeed presents cases of incest, adultery, and, even amid patriarchal domination, marital conflict. Though these stories illustrate that the human concern with family matters is not a problem in modern times, the kind of guidance they offer to families living today is controversial. Here, advice is given to the 
care practitioner that he/she must search for the central features of the Christian message about the family and focus on the center as against the peripheral elements that are also in view [6].

Through the clinical model, psychological theories have been utilized to illuminate certain important issues regarding special relationships. Psychoanalysis affirmed the centrality of human sexuality and emphasized the power and potential destructiveness of family relationships, including how they can be carried over from the past into the present. On the other hand, family therapy, seeking an alternative to the focus of psychoanalysis had embarked on freeing the individual from bondage to the family. Their emphasis has been based on the fact that family members are related to one another systematically, rather than historically. Within this family therapeutic work, therapists have often specialized in these three areas: those concerned with communication within the family system; those who emphasized the importance of family structure; and those who focused on how the individual could be empowered to be an individual despite the power of the family system. The applications of Winnicott's theory of object relations by some American psychotherapists have agitated some of the influence of both Freudian psychoanalysis and the family-system theories. Unlike the latter last-mentioned theories, object relations theory emphasizes the importance of both the individual and family relationality. Several scholars utilizing this theory have come up with the notion that an individual can be unique, the individual self, and at the same time be also related to others in unique relationships. Two keywords are vital when it comes to special relationships: closeness and intimacy. Both closeness and intimacy are needed in a relationship if it has to survive. Through a sociological analysis, Berger states in his work that the intimacy and closeness involved in special relationships are best facilitated by the construction of a common world through conversation [7]. The work of Lyman and Adele Wynne which sought to explain clearly the word "intimacy" comprehend it as a subjective relational experience in which the core components are trusting self-disclosure and communicated empathy [8]. Malone and Malone see both closeness and intimacy as vital and, therefore, inseparable. According to them, a balancing of closeness is necessary for any relationship that is special. Without closeness, they assert, intimacy would be chaotic. Without intimacy, closeness would and does insidiously deteriorate into role-playing and boredom [9]. Whereas the prototype of closeness is a personal experience, in the sexual experience both persons are much more aware of themselves than they are of the other [10].

The most important thing to know concerning the communal contextual model (here, healthcare takes its model) is the awareness, on their part, to look to the communal contextual for a critique of their assumptions about what is normative for special relationships. In Patton's judgment, the practitioner carer must be careful, and aware of what is universal and what is particular in patterns of family life, particularly about what ought to be. Patton has written that intercultural and interracial study of the family is important in assisting practitioners in their understanding of what is universal and what is particular in patterns of family life. Particularly they must know about what ought to be. Patton believes the structure of adequately functioning families varies greatly. Rather than being overly troubled that a family structure differs from his/her own, the carer can helpfully inquire about and discuss the balances of care among the generations of the family and the balance between care for oneself and care for others to whom one is specially related [11].

\section{Swedish Healthcare Focuses on Therapy}

The Healthcare system developed by the Swedish is not focused on relationships alone but also focused on therapy, which is, treating and nurturing the person. This is the reason why I find it necessary to discuss psychotherapy. Psychotherapy is more readily employed where the objective of "constructive change" makes more deliberate and consistent use of psychological mechanisms and processes. In psychotherapy, the "caring relationship" is put on a more professional basis (implying education, expertise, dedication, responsibility, and membership of a relevant institution on the part of the therapist) "[12]. Here, biomedical scientists dominate in bringing treatment to many people involved in healthcare. Stein's work entitled Guilt: Theory and Therapy explores the necessity for understanding our guilt and its application in psychiatry, psychology, sociology, and religion. He studies in depth the ordinary individual, the sociopath who does not suffer from guilt, and the neurotic who feels over-guilty. In where he discusses "Guilt in the Sociopathic personality" [13] he says the American Psychiatric Association defines "psychopath" as a person whose behavior is predominantly amoral or anti-social and characterized by impulsive, irresponsible actions satisfying only immediate and narcissistic interests, without concern for obvious and implicit social consequences, accompanied with minimal outward evidence of anxiety or guilt [14]. Sociopathic personality is a precise term and one can have it into four subheadings:

a) Antisocial reaction,

b) Dyssocial reactions,

c) Sexual deviation and

d) Alcohol and drug addiction.

McCords, on the other hand, without depreciating the value of the precision in the diagnosis of its obvious clinical value, focuses on aggressiveness, guiltiness, affectional shallowness, and extreme impulsivity" as a central core of the psychopath's syndrome [15]. They emphasize guiltlessness and lovelessness as the two traits which "conspicuously mark the psychopath as different from other men [16]. Cleckley attributes the following characteristics to the primary psychopathic personality: 
a) Unexplained failure.

b) Undisturbed technical intelligence.

c) Absence of Neurotic anxiety.

d) Persistent and inadequacy Motivated Antisocial behavior.

e) Irresponsibility.

f) Peculiar inability to distinguish between truth and falsehood.

g) Inability to accept blame.

h) Failure to learn by experience.

i) Incapacity for love.

j) Inappropriate or fantastic reaction to alcohol.

k) Lack of insight.

l) Shallow and impersonal Responses to sexual life.

m) Suicide rarely carried out; and

n) Persistent Pattern of Self-defeat [17].

Piers and Singer (1971), from a psychoanalytic orientation, distinguish between shame and guilt properly. The following seem to be properties of shame that differentiate it from guilt:

a) Shame arises from a tension between the ego and the ego ideal, not between ego and superego as in guilt.

b) Whereas guilt comes whenever a boundary (set by the superego) is touched or transgressed, shame occurs when a goal (presented by the ego ideal) is not being reached. It thus indicates a real "shortcoming." Guilt anxiety accompanies transgression, shame, failure.

c) The unconscious, irrational threat implied in shame anxiety is abandonment and not mutilation (castration) as in guilt.

d) The law of Talion does not obtain in the development of shame, as it generally does in guilt [18].

\section{Summary of the Review}

The behavioral feature which is conjoint with every Swedish home is independence. Healthcare taking of the elderly, as well as the prisoner, adapt to this common characteristic. When caretaking occurs to the elderly in their homes and the prisoner in his cell, it allows them to enjoy corporate independence. It consoles family members to have their peace of mind knowing that their loved ones will receive superb care and love, even in the prisons with professionals, such as biomedical doctors, nurses, physiotherapists, dentists, dieticians, psychologists, etc. In addition to this, the seniors choose to stay at home or join a nearby care company where several elderly persons live. Biomedical doctors and nurses all play their part in the healthcare industry. They prescribe the drugs and provide healthcare with outstanding involvement. The care where the elderly, as well as the prisoner, receive their choices can be attributed to the fact that the elderly and for that matter, all persons, have contributed to their various communities where they once lived. They have worked day and night, raised their families, and paid their taxes, according to the laws of the nation. The citizens deserve to receive the same high quality of healthcare. In addition to the care the elderly receive, healthcare workers are needed and appreciated. They receive good income and training to make them feel good and professionally oriented. So it is a win-win situation for everybody. The elderly, the prisoner and their families, as well as all current and futures citizens of Sweden, wins.

\section{Methodology in the Empirical Studies in Health Care}

The empirical studies I conducted in the health care industries did not take place on one occasion. Between 1995 and1998, I conducted empirical investigations into welfare care in Swedish prison institutions. I got permission from the Andliga Vard within Kriminavaden to investigate immigrant inmates in Kumla Prison, Hiseberg Prison and Norrtaije Prison. These are very strong institutions that have been classed as classes 1-3. In Hinseberg Prison, I researched the only prison institution where they keep women in the country. I worked and gained experiences in the health care industries and psychiatric wards, which were the Scarpnadcare AB, which was a private institution in the Stockholm region, and the Sodertailje Psychiatric ward, which was a public institution. Finally, in Uppsala Region, I gained experience in the District's Elderly Care, Karl JohanGarden Elderly Health Care, for which Uppsala Municipality was responsible.While in the Welfare Prison Institutions, I got appropriate permission from the Kriminalvarden in Sweden to conduct research and gather empirical material in the Scarpnadcare AB, Norrtailje Psychiatry, and Karl JohanGarden I did not seek any permission. Therefore, I can only present data in the first-mentioned health care publicly and for the rest of the data, I will employ my own anonymous work experiences without using specific data from them. This is because I have to observe the code of ethics, which is known as tystsnadplikt. The interview method has some problems though it is a more systematic way of gathering data. Through a better-structured technique, one can have more objective data, which can eventually be helpful for the investigation and control of mistakes. Despite this advantage, according to Hyman et al. [19-21], the interview method has some problems, which often result when they are not applied carefully. The formulation of the questions can create a special kind of expectation with the respondent, which he can live up to. The interviewer's way of framing the questions can reveal his values which can influence the respondent. The interviewer's characteristics such as sex, age, and a social group can mean much for the respondent's answers. 
Attitudes of the interviewer and values can be believed by the respondent. The interviewer's expectations concerning the answers of the respondent can elicit certain answers. The interviewer's equation can influence the respondent [19]. Furthermore, the role between the interviewer and the respondent can be changed in different ways as situational disturbances arise. Such as the interviews' variation as it concerns the penal systems of individual questions and interview variations as it concerns the jotting down of notes can create unreliability. According to Hyman et al. [19-21], one can avoid some of these mistakes if a researcher uses the services of a trained interviewer in gathering his data [20]. In this study, also utilized the questionnaire method because it has an advantage over the other methods. In that, it reduces the importance of the interviewer. The interviewers' personality as able to influence the answers respondents to give does not come. Complications, which often arise during the communication process, disappear. The questionnaire technique is the most structured and standardized method, and that was one of the main reasons I resolved to utilize this in my data collection [21].

Finally, I used the observation method in the rest of the healthcare wards, where I did not seek permission. I depend on my anonymous data to convey information that should answer my questions. The observation aimed at experiencing the ward situation, worship services, treatment programs, and leisure activities for the patients. Some researchers describe behavior observation as entailing methodological consequences. There is also unanimity among researchers that the formerly procedures, i.e., questions, tests, files, and institutional analyses, portray reality to an even lesser degree than would be expected through observation [22]. The choice of observation could indeed have helped me to view certain partial aspects of such a complex field, yet I could not embark upon it as I had wanted due to certain restrictions. Though it portrays a better reality, the observation method is the less structured and less standardized approach to collecting data. Criticisms leveled against the observation method are that often a researcher can build his observation upon wrong sources. Since many of the things under observation are not directly accessible to our eyes, for example, thinking and emotions, scholars advise the use of interview techniques. The sample includes 74 chaplains and 52 inmates who participated in the investigation, making $126(\mathrm{~N})$ participants. The total response rate of all the respondents was good. When I compare my results to other researchers' work in survey research, the results of my work seem normal and satisfactory. Again, if we understand that there are many restrictions placed on prison research, then we could say that the response rate was, on a whole, satisfactory.

\section{Statistical analyses and the Validity and reliability of the Data}

The question of validity draws attention to how far a measure measures the concept, which it purports to measure. The reliability of a measure refers to its consistency. In the prison research, inmates suspect researchers who approach them as agents of the police force. Such suspicion leads some inmates to give false and misleading answers to questions presented to them by researchers. In this research, however, I made it clear to the inmates who I was, repeating to them that I was a private researcher who intends to interview them about the work of the chaplains and how it affects their day-to-day life in the prison. It indeed affected the reliability of the data or the information elicited from them. I attempted to formulate the questions presented to these respondents as clearly and neutrally as possible. I avoided asking too many questions to both the chaplains and inmates. I conducted a pilot study before I decided on the final versions of the questionnaires. The statistical analyses employed were Analysis of Variance (ANOVA) and Regression analysis. The SPSS aided me in dealing with the study's aim. ANOVA as an omnibus allowed me to work with causal relationships between several variables. Regression is a powerful tool for summarising the nature of the relationship between variables and for making predictions of likely values of the dependent variable. It is the most widely used method for conducting multivariate analyses, particularly when more than three variables are involved. Regression allowed me to look for predictive powers between the independent variables and the dependent variables.

\section{Results}

\section{A Day in the Elderly Care at Karl Johangårdet in Uppsala}

The care of the elderly receives superb organization and accountability, which the CEO champions herself. Her profession is a nurse. Each elderly has her/his apartment except those couples who have agreed that they would stay in the same room. The CEO has her secretary and an accountant who keeps the financial management. Apart from these two persons, there are the biomedical doctor, nurse, psychologist, physiotherapist, and the other nursing assistants and mental carers who make up the large number of the personnel who work there. The elderly persons have their daily treatments and consultations with these biomedical professionals during their breakfast and lunch. Sometimes these professionals visit the elderly daily in their apartments to treat them. They want to find out whether they are in good health and are taking their prescribed medicines. These professionals run a shift system whereby some personnel work at night. Other nontreatment activities include cultural activities, visitation by their family members, worship services, excursions to famous places, such as famous cathedrals and burial sites. The one behavioral characteristic which is with every Swede concern independence. Caretaking of the elderly adapts to this common characteristic even among these seniors. The caretaking of the elderly in their homes allows them to enjoy this independence. It consoles family members to have their peace of mind knowing that their loved ones will receive superb care and love from professionals. In addition to 
this, the seniors have other options to choose to stay at home or join a nearby care company where several elderly persons live. Apart from the independence characteristic that steers the living and the treatments, the whole healthcare principle focuses on relationality and therapy.

\section{A Day in Scarpnadcare AB (Behandinghem) Treatment Homes and Sodertäilje Psychiatric Ward}

Scarpnadcare $\mathrm{AB}$ is a private company where drug addiction patients live and receive their treatments while responding to wellness. Sodertälje Psychiatric Ward is a typical Psychiatric ward where inmates/patients receive treatment. The Sodertälje Psychiatric Ward is public where the government is the investor in the production business. But the private company, that is, Scarpnadcare $A B$, has several other wards, such as the elderly and mental patients who have serious illnesses such as diabetes, Alzheimer's disease, High blood pressure (BP), etc. These patients cannot take care of themselves. Professionals such as biomedical doctors, nurses, psychologists, physiotherapists, etc., do the treatments in both companies as a team. The others are nursing assistants and mental carers who make up a large part of the personnel. Those patients who receive care for their addictions are in the open homes, which means they are free to go out and come in so far as they obey the rules in the ward/living area. Many of these patients receive pensions and social support from the Social Security Authority and Social support Authorities. These authorities are instrumental in bringing them to these treatment centers for treatment purposes and enjoying Swedish healthcare. Other non-treatment activities include attendance to cultural activities, visitation by family members, worship services, excursions to famous historical areas, such as famous cathedrals and burial sites during the summer months. But those in treatment centers seldom participate in church activities as they may be patients with different backgrounds such as Moslem, Orthodox Church, Methodists, Presbyterian, etc. The independence feature shows that the treatment and procuring of healthcare base their premise on relationality and therapy.

\section{Remarks on Biomedical Science, Personnel and Research}

We mentioned at the outset that the development of healthcare in the Elderly care and Psychiatric ward could not have been successful without the contribution of biomedical science, its personnel, and research. In the above analyses, experiences in the wards where patients and elderly are constantly undergoing treatments indicate that the Swedish welfare system is tremendously dependent on the ideas of the biomedical professionals that function as curers and managers in managing these industries. They also conduct successful research to look for appropriate manners where patients could receive maximum care. We see the involvement of biomedical research, its personnel, and the way it has championed new knowledge and confidence in the industries as a whole as indispensable. They are the CEOs who manage the healthcare industries and organize conferences that look for progress on the way. The Social Steering Board (Social Styrelsen) comprises men who possess enormous political experiences and biomedical scientists who have extensive knowledge in research. They carry out programs that steer and manage the welfare programs in the Elderly and the Psychiatric Wards. Let us now turn to the welfare in the Prison institutions, where I used questionnaires and interviews to gather data. The study aimed to show progress and treatment outcomes in the welfare of the prisoners in the institutions. The work will depend on the recent empirical materials that I have collected through rigorous analyses and investigations. Even here, the study will unveil the stupendous development which biomedical science, its personnel, and research have generated to continue progress in healthcare.

\section{Welfare Organizers and their functions in the Prison Institutions}

The prison chaplains perform different functions in prisons for the inmates, which include psychological counseling and support in treatment. As one begins to consider these functions, there appear some salient ones that are prominent and worth mentioning. In my attempt to measure them, I came up with seven essential ones, which feature prominently. In this investigation, I presented seven roles in the questionnaires with alternative answers. The Example role is measured "modeling a pattern representative action, or a series of actions tending or intended to induce imitation or emulation. This denotes how to give concrete embodiment to one's manner of showing his spirituality." Availability represents "having time and willingness to be personally accessible for pastoral care and counseling." Teaching: "Instructing, causing someone to know a subject, or accustoming a person to some action or attitude." Administration: "Employing principles, practices, and rationalized techniques, policies, procedures in achieving the objectives, and aims of an organization." Advice: "Making a recommendation regarding a decision, direction, or course of conduct, or making the decision for the other person." Preaching: measures the work of "Discoursing publicly on a religious subject or from a text of scripture, delivering a sermon or homily." Counseling: Guiding an individual to a better understanding of his/her problems and potentials." Other: "An opportunity for unique expressions by responders that might not be included in the previous categories." Let us present these roles and their percentages of importance. $37 \%$ of the chaplains chose the variable "Example," that is, the role of the chaplain as being in the prison to set a good example to the inmates as "Very important" in the work among inmates.

About 21\% chose "Quite important." Only 26\% were "undecided," "Not very important," 5\%, and "Absolute not important" $11 \%$. There was not much difference as regards the chaplain's work concerning his being ready and available to the inmates and the 
staff. "Availability" was regarded as an important role by $35 \%$ of the chaplains and 7\% viewed it as "Absolutely not important." Among the roles, "Teaching," "Administration" and "Preaching" received very low percentages in the "Very important" category. The percentages were $3 \%, 6 \%$, and $6 \%$ respectively. The "Counselling" role received a higher percentage; $87 \%$ of these chaplains reported that counseling inmates in the prison are a "very important" work. If we add the "Quite important" function to the former it means that $92 \%$ of those who answered the questionnaires indicated that the counseling work is "important" as against "not important" and "undecided" which had a total of $8 \%$. The rest are "Availability" 74\%, "Example" 58\%, "Advice" 51\%, "Others" 33\%, "Teaching" 32, "Preaching" 20\%, and "Administration" 20\%. The results of this investigation show that the majority of chaplains are aware of their being in the prison to provide healthcare and counseling to the inmates. According to this work, this is their notable task, and indeed it is demonstrated very often in their work. It is no wonder that they spend a great deal of their time to care and counsel and also give professional support to inmates who find themselves in crisis. They also provide available support to the inmates when they are receiving treatments from other biomedical professionals in the prison institutions. The results of the investigation showed that though the proportion of men (86\%) to women (14\%) was 6 times higher than the women (6:1), women, as well as men, found the "Counselling," "Example" and "Availability" as the most important roles in the work among the prisoners.

\section{Organizations Attitudes and the Roles}

It is also worthwhile to examine the two different organizations and their attitudes towards the four most important roles and healthcare in the prisons. We have already pointed out that the Church of Sweden's chaplains makes up $50 \%$ of all the chaplains who participated in the investigation. The remaining $50 \%$ are from the Free Churches, which comprise The Swedish Mission, The Pentecostals, The Salvation Army, The Orthodox Churches, etc. By variance analysis, a comparison was made between the mean scores of "counselling," "example," "advice," and "availability" by the four church organizations' chaplains. The results are presented in (Table 1). For example, the one on counselling shows that the degree of freedom "between groups" is 3, and that of "within groups" is 30 which makes a total of 33 . The mean square between groups is 1.0354 and within groups 0.6925 . By dividing the former by the latter, we get the F Ratio 1.4951 and a probability level $\mathrm{p}=$ 0.2359 which is non-significant $(p>0.05)$. Therefore, there are no significant differences in the mean scores of counselling between the four church organizations. The probability levels of the variable Example ( $\mathrm{p}=0.0874)$, Advise ( $\mathrm{p}=0.8106)$, and Availability variable $(0.5485)$ is non-significant at $p>0.05$, meaning that there are no significant differences between the means scores of these variables.

Table 1: One-way analysis of variance for comparing four church organization's means scores on the four important functions.

\begin{tabular}{|c|c|c|c|c|c|}
\hline Organizations & $\begin{array}{c}\text { Counseling } \\
(\mathbf{n}=\mathbf{3 7})\end{array}$ & $\begin{array}{c}\text { Example } \\
(\mathbf{n = 3 7})\end{array}$ & $\begin{array}{c}\text { Advice } \\
(\mathbf{n}=\mathbf{3 7})\end{array}$ & $\begin{array}{c}\text { Availability } \\
(\mathbf{n}=\mathbf{3 7})\end{array}$ & Organisation G. Means \\
\hline Chur of Sweden & 4.82 & 4.00 & 3.23 & 4.11 & 16.16 \\
\hline Swedish Mission & 5.22 & 5.33 & 3.44 & 4.77 & 18.76 \\
\hline The Baptist ch. & 5.00 & 2.66 & 3.00 & 3.75 & 14.41 \\
\hline Other churches & 5.75 & 4.00 & 3.75 & 4.25 & 17.75 \\
\hline Function Means & 20.79 & 15.99 & 13.42 & 16.88 & 67.08 \\
\hline
\end{tabular}

The Healthcare workers on the Social Situation in Prison

The professional code of ethics cautions the caregivers to be silent concerning what transpired between them and the inmates during their counselling support. This professional secrecy has already been discussed in the work. This code also bars them from making use of materials ascertained during a counselling session. While making use of their experiences with inmates is prohibited, these carers cannot forget the effect of some of these bad experiences that happen to the inmates. The worries over these bad experiences cannot be shown publicly. On the contrary, they feel deep inside as they go about their work. Results show that they perceive the effect of some of these experiences on their minds in their day-to-day life. It is a way of asking for and seeing how the carers as human beings perceive and share the sorrow of these inmates they often come into contact with. There were some worries concerning the way some inmates are arrested, sentenced, and put in prison. Together $6 \%$ of the chaplains indicated their "great worry" and 33\% "quite worry" which is a total of 39\% over these problems which certain inmates face before their sentence. However, 61\% which includes those who "neither feel worried nor concerned", "Not much worry" and "No worry at all" objected to the fact that this is something that has effects on their minds. On the other hand, concerning the case of illness or sickness of inmates, 53\% of these chaplains find it a "worry" on their minds. This shows that the chaplains are more concerned about inmates' health and well-being than how the process of the law has been executed to the cases of these inmates. When we turn to the 
"emotional problems of immature inmates" a higher percentage of the chaplains $67 \%$ agreed that this worried them while $25 \%$ were "undecided" and 8\% disagreed that it is a problem to be worried about. This is understandable, as the chaplains are there purposely to help inmates who have problems of emotional nature. It is an interesting result which, however, authenticates why they are there in the prison to help cure and support the sick souls. There are other problems that the results showed that they were concerned about and are worried over them. Some carers become worried, over the case of "Physically handicapped" 43\%, "Alcoholics" 48\%, "Drug addicts" 59\%, "Issues about parole" 59\%, "Inconsistency in judgment or sentencing" 52\%, and "Preparation for release" $36 \%$. Also, "How the length of an individual sentence should be" $60 \%$ and "The cases of those to be deported away from their families," $86 \%$. The worries over the cases of drugs, about parole, inconsistency in the procedure of sentence, the length of sentences for inmates, and the deportation case are worth noting.

As statistics show, immigrant inmates go to prison due to drug trafficking or drug problems. The chaplains render altogether $80 \%$ of their services among these immigrant inmates; therefore, the chaplain acknowledging here that drug comprises one of the greatest worries is significant. Moreover, when one realizes that drug cases are among the cases that obtain maximum sentences. As the decision of an individual being granted parole depends on the factor of good behaviour, the involvement of the chaplain is paramount. This is understandable if the issues involving parole are also a great worry to the chaplain. Ethical conduct lies in the domain of the chaplain, and this and other matters will constantly come before him. This investigation shows that problems entailing inconsistency in sentencing worry the chaplain. About $52 \%$ of these chaplains accepted that they comprise one of their worries and this is indeed the case. Among immigrants, a higher percentage of them believe that they are innocent and that the authorities have judged them wrongly. In prison, these unfortunate inmates constantly contact the chaplains and request their help. Some want the chaplain to write direct or assist them in writing to the authorities so that their cases will be looked into.

It seems many of these chaplains by their contacts with these inmates become engrossed in these problems as they are confronted with the truth about certain matters relating to the cases. The length of time for imprisonment was accepted by $60 \%$ of the chaplains that it was a problem that worries them. This is understandable because immigrant inmates often receive higher or maximum sentences because of drug involvement. The chaplain who is closest to them these inmates will contact him to do something about it for them. The chaplains face inmate's deportation as the greatest of all their worries. "Worry" could mean how often the inmates approach the chaplains for help concerning a particular problem. It could also mean that the chaplains involve themselves in the cases and become worried and, while helping others, become emotionally involved. Together $86 \%$ of the chaplains see this problem as a worry to them, and they show emotion with several cases that concern inmate's deportation. This result is particularly relevant as the investigation, which utilized in-depth interviews, uncovered a strong reaction by the chaplains. A focusing interview with one energetic chaplain revealed that they sent a couple of letters to the appropriate authorities objecting to the deportation of inmates to their various countries even when they know that these countries are stable. The scores of the chaplains' attitudes towards the social problems of inmates were analysed further with factor analysis. Inter-correlation among the items reveals that all except one of the variables correlate with each other. Correlation analysis confirms the fact that there is an internal connection among the variables of social situations. These relationships motivate us to investigate further with factor analysis. Factor analysis is primarily concerned with describing the variation or variance, which shares by the scores of people on three or more variables. It shows us how the variables or items are connected. The results of the statements show that there is a systematic pattern of the answers to the material. In one way it can be described that there is an underlying factor, which is behind the answers to the questions. That is, all the chaplains portray in their responses that they are human beings and, as a result, care for the inmate's problems. It seems they all agree to and respect one important value of their profession; the care for individuals who are in deep trouble, and this is the reason they get worried over these problems.

\section{Social Situations, Coping Strategies and Cultural Problems in Prisons}

During interviews with the chaplains, it was revealed that some of the inmates usually get disturbed over how cases involving crimes committed are settled. One pastor expressed this to me: The inmates often come to me and complain about how the Swedish Criminal Justice System is not fair to them. In one case, for example, the inmate complained to me how he would have wished to get access to some law books from the library so that he could go and find out whether a person could be tried twice on a single case. It is a lack of understanding of the Criminal Justice System that presents a problem to the inmates. But we do our best to counsel them to have patience. Cases involving the deportation of inmates to their various countries often come to the attention of chaplains. Here a chaplain says this: The inmates consult me before they go to the authorities to listen to whether they will deport or not. This is always a sad situation. The case of one inmate who came to me before the deportation can be narrated.

We prayed that God should be with him as he goes through this difficult situation. I also advised him that God knows that nothing will happen which is why probably he has allowed the authorities to come to such a decision. But still, the inmate was afraid. Some chaplains protested the deportation cases. In the interviews, we 
find these: Sending them back to their countries does not solve the problems. I think the authorities should reconsider this law and make some changes. Inmates with families and have responsibilities should be made to go under training. They should teach them about the Swedish culture and other necessary social life. Some inmates have received bad news from friends who they sent home. Some were beaten and received severe injuries, others died due to bad treatments they received when they got to their destinations. These extracts are just a few of the many responses I received from the chaplains concerning the inmate's social situations in prisons. There are other cultural difficulties that the interviews of the chaplains make us more aware of. There are cultural misunderstandings that the inmates contact the chaplains for their clarity and support. One carer has this to say: Some inmates feel embittered when they go to prison because of a mere quarrel with their wives. In many other cultures, the wife is the property of the husband. These inmates feel that they have the right to beat their wives when they misbehave. They do not see why the authorities should arrest them. This belief is at variance with Swedish law, which states that every person must respect his/her neighbour. No one is another person's slave.

\section{There is Another Problem that Concerns the Food They Eat in the Prisons}

The majority of immigrant inmates find it a problem to adapt to prison life. It has to do with the foods that they give to them. They are used to their cultural diet at home. In prisons, they eat all foods that the authorities give to all the inmates. This behaviour makes some inmates cook or prepare their dishes that affect their meagre economy in prison. Thus, this lack of understanding concerning the cultural problems and their inability to adapt to prison life makes the immigrant inmates all the more miserable in prison.

\section{Predictive Value of Welfare Careers on Adaptation in Prisons}

Regression is an important method to study the relationship between variables and for making predictions of likely values of the dependent variable. It is the most extensively used method for conducting multivariate analyses, particularly when more than three variables are involved. In Tables $2 \& 3$, multiple regression analyses were employed to find the significant predictors of changes in attitudes and behaviours of inmates. The simple stepwise multiple regression analyses were performed using two groups of independent variables. In the first place, in Table 2 , the variable changes in attitudes and behaviours were used as dependent variables while religious affiliation, church attendance, religious service observance, motivation and support, deeply felt positive mood and age was employed as independent variables. None of the variables was forced into the equation. The multiple correlations (independent variables collectively correlate with the dependent variable) for the multiple regression analysis was $\mathrm{R}=0.63$. Regression equation $\mathrm{F}$ ratio was $\mathrm{F}=9.15778$ and its significance was $\mathrm{p}=0.0009$ i.e., $\mathrm{p}<0.001$. The explained variance was $40 \%$, and the unexplained variance was $60 \%$. The results of the analyses revealed that only deeply felt positive mood (B coefficient $=1.08)$ and church attendance $(B$ coefficient $=-6.75)$ have significant predictive powers about changes in attitudes and behaviour. In Table 3 changes in attitudes and behaviour remained as the dependent variable while the usefulness of the chaplains' work, the expectation for the chaplains' work, religious observance function, the inner room of the church's function, pastoral care, sensitivity to human needs, motivation and support, and deeply felt positive was employed as independent variables. Like the previous analysis, none of the above variables was forced into the equation. The multiple correlations for the regression analysis were $\mathrm{R}=0.54$. The equation had $\mathrm{F}$ ratio ( $\mathrm{F}=12.12061, \mathrm{p}=0.0016$, i.e., $\mathrm{p}<0.001$ ). The explained variance was $29 \%$ and the unexplained variance was $71 \%$. The findings of this multivariate regression analysis showed the usefulness of the chaplains' work as having significant predictive power about changes in attitudes and behavior (B coefficient $=0.80$ ).

Table 2: Multiple regression analysis with changes in attitude and behaviour as the dependent variable and religious affiliation, church attendance, religious service observance dimension, motivation and support dimension deeply felt positive mood dimension and age as the independent variable.

\begin{tabular}{|c|c|c|c|c|c|c|}
\hline Dependent step variable & Indep. variables regression & Regression & $\begin{array}{c}\text { Standardized Coefficient } \\
\text { (Beta) }\end{array}$ & $\begin{array}{c}\text { B } \\
\text { Coeff. }\end{array}$ & t. & $\mathbf{P}$ \\
\hline $\begin{array}{c}\text { Changes in Attitude \& } \\
\text { Behaviour }\end{array}$ & 1 & $\begin{array}{c}\text { Deeply felt } \\
\text { positive Mood }\end{array}$ & 0.60 & 1.08 & 4.01 & 0.0004 \\
\hline $\begin{array}{l}\text { Changes in Attitude \& } \\
\text { Behavior attendance }\end{array}$ & 2 & Church & -0.33 & -6.75 & -2.19 & 0.0373 \\
\hline
\end{tabular}


Table 3: Multiple regression analysis with changes in attitudes and behaviour of inmates as the dependent variable and the importance/function of the chaplain's work, the expectation of the chaplains' work, religious service observance function, the inner room of the church function, pastoral care, sensitivity to human needs, motivation and support and deeply felt positive mood as independent variables.

\begin{tabular}{|c|c|c|c|c|}
\hline Dependents Variable & Indep. Variables & Beta Coeff. & B Coeff. & t \\
\hline Change of & $\begin{array}{c}\text { Function of the } \\
\text { chaplains' work. }\end{array}$ & 0.54 & 0.80 \\
\hline Attitude \& $1 \quad$ Function & 0.0016 & 3.48 \\
\hline
\end{tabular}

\section{Discussion and Direction for Future Research}

The study commenced with a general proposition that the chaplain's/carers' work will have influenced the attitudes and behavior of the inmates in the prison institutions. The two hypotheses were: The variable "usefulness of the chaplains' work" will have a positive effect on the variable "changes in attitudes and behaviors." And the variable "deeply felt positive mood" and the variable "church attendance" will have a positive effect on the attitudes and behaviors of the inmates. These data were condensed into dimensions before the main hypotheses could be worked with using the regression analysis method. The work utilized the Oneway variance analysis to compare the mean scores of the carers' roles among the groups of inmates. First of all, the prison chaplains perform different functions in the prisons for the inmates. These include psychological counselling and support in treatment with other biomedical professionals. These functions appear to be prominent and worth mentioning. They are to be there as an example; they must be available; teaching, administration, advice, preaching, and counselling. Psychological counselling seems to be the most essential of all than the other functions in prisons. While making use of their experiences with inmates is prohibited, according to the professional code, these carers cannot forget the effects of some of these bad experiences that happened to the inmates. The carers do not display the worries of the bad experiences publicly. On the contrary, the carers feel them deep inside as they go about their work. These social problems concern the problems with the criminal justice system, problems with their culture, drug offense problems and sentencing, and many others.

These carers do their utmost best to support them. They also help in their treatments when the biomedical professionals are doing that. I used correlation to strike the relationship of the background factors such as continent of origin, citizenship, religious affiliation, type of offense, years of imprisonment, and church attendance to the (dimensions) variable expectation and usefulness. These, however, revealed no statistical relationship in any of the variables. However, a stronger positive relationship happened between church attendance and expectation. The usefulness of the work and types of the offense had a stronger negative relationship. Positive associations between age and the dimensions showed a significant relationship (though age-related strongly and negatively with usefulness, religious observance, and the inner room of the church functions). These positive associations compelled me to use the regression analyses to pursue the rest of the statistical analyses. The results of the inter-correlation of the variables (dimensions) revealed that expectation, usefulness, and deeply felt positive mood correlated significantly higher with most of the variables. The significant inter-correlation was the force behind the use of multiple regression analysis (i.e., to investigate whether there were associations between some background factors and changes in attitudes and behaviour.) Again whether there was an association between the dimensions and changes in attitudes and behaviour. In two multiple regression analyses, deeply felt positive mood and usefulness of the chaplains' work were significantly and positively associated with changes in attitudes and behaviour. Only church attendance was negatively significant with changes in attitudes and behaviour. This finding is of interest because the government and the church spend money to enable the prison chaplains to function better in prisons. These findings will support the fact that the chaplains' work must go on among the outside communities, but also the inmates themselves. It is interesting to listen to the inmates at the most security-oriented prisons described their appreciation of the chaplains' work. It is in these closed prisons where they keep inmates who get longer sentences. It is probably more rewarding to be more active as a prison chaplain for these inmates. Example from an interview with one female immigrant inmate (L) on how she recognizes the importance of a chaplain work goes like this: It happened one and half years ago when the father of my daughter died. A man shot him in my country. When I heard the news, I informed the chaplain about it. Then we had a memorial service for him in the church service. At that time, the church members were the only people who supported me. We lighted candles for my former husband. I felt very well again. The chaplain was a great source of help to me at that time in prison. It is always nice to have the opportunity to go to church and pray to God. I hope that there will be a chaplain in the prison environment always all the time. There is a need for a chaplain in this prison. The present study indicates that the chaplains' work associates with attitudes and behavioural change that immigrant inmates experience in prison. This behaviour symbolizes the great work of healthcare they do in the prisons. This change may be the cause why some inmates do not consider committing suicide but can cope with life and the 
difficulties they face in the prison environment. Previous church attendance before imprisonment may help very little as compared with the chaplains' functions. Together with the mood positivity of the inmates (which results from the chaplains' work), these can make inmates live happily in prisons forgetting now and then their troubles. Inmates also give up that behaviour that does not help them to cope or adjust. The two predictive factors, the usefulness of the chaplain's work and deeply felt positive mood tell us that the work of the carers in prison is significant not only to the public healthcare but also to the inmates coping strategy.

\section{Ethics Declarations}

Ethics approval and consent to participate: Permission was given to the researcher by the Swedish Agency that deals with Kriminalvarden and the National Crime and Probation Administration. Therefore, I acquired permission. Moreover, I tried to hide the identities of the individuals. Informed Consent and Anonymity complied.

\section{Consent for Publication}

Not applicable

\section{Competing interests}

The author declares no competing interests.

\section{References}

1. Lesperance, Martina (2014) Sweden: A Role Model for Elderly Care. Global Health Aging. Gobalhealthaging.Org

2. Swedish Elderly Care System aims to help People Live Independent Lives. Elderly Care in Sweden. Sweden.se;

2.1. Peprah E, Wonkam A (2013) Biomedical research, a tool to address the health issues that affect African populations. Globalization and Health 9: 50

2.2. (2002) World Health Organization. Advisory Committee on Health Research: Genomics and world health: report of the Advisory Committee on Health Research. Geneva: World Health Organization.

2.3. Lim SS, Vos T, Flaxman AD, Danaei G, Shibuya K, et al. (2012) A comparative risk assessment of burden of disease and injury attributable to 67 risk factors and risk factor clusters in 21 regions, 1990-2010: a systematic analysis for the Global Burden of Disease Study 2010. Lancet 380(9859): 2224-2260.

2.4. Singer PA, Daar AS (2001) Harnessing genomics and biotechnology to improve global health equity. Science 294(5540): 87-89.

2.5. Seguin B, Singer PA, Daar AS (2006) Science community: scientific diasporas. Science. 312(5780): 1602-1603.
3. Asserhed R (1990a) Den Andliga Vården inom Kriminalvården in R Asserhed (Eds.), Den Ömma Punkten, Stockholm: Verbum.

4. Kriminalvård Sverige (1995) in Asserhed R (1990a) Den Andliga Vården inom Kriminalvården in R Asserhed (Eds.), Den Ömma Punkten, Stockholm: Verbum.

5. Asserhed R (1990a) Den Andliga Vården inom Kriminalvården in R Asserhed (Eds.), Den Ömma Punkten, Stockholm: Verbum.

6. Patton J (1993) Pastoral Care in Context: An Introduction to Pastoral Care, Louisville, Kentucky: John Knox Press: 188.

7. Berger PL (1977) Facing up to Modernity: Excursions in Society, Politics and Religion, New York: Basic Books: 7.

8. Wynne L, Wynne A (1986) The Quest for Intimacy. Journal of Marital and Family Therapy 12: 383-394.

9. Malone TP, Malone PT (1987) The Art of Intimacy, New Jersey p. 49

10. Malone TP, Malone PT (1987) The Art of Intimacy, New Jersey p.64.

11. Patton J (1993) Pastoral Care in Context: An Introduction to Pastoral Care, Louisville, Kentucky: John Knox Press. pp. 188.

12. Stein E (1968) Guilt: Theory and Therapy, London: George Allen \& Unwin Ltd. p.86 f.

13. Stein E (1968) Guilt: Theory and Therapy, London: George Allen \& Unwin Ltd.

14. Stein E (1968) Guilt: Theory and Therapy, London: George Allen \& Unwin Ltd.

15. Stein E (1968) Guilt: Theory and Therapy, London: George Allen \& Unwin Ltd.

16. Stein E (1968) Guilt: Theory and Therapy, London: George Allen \& Unwin Ltd.

17. Stein E (1968) Guilt: Theory and Therapy, London: George Allen \& Unwin Ltd.

18. Narramore SB (1983) Guilt in HN Malony (Eds.), Wholeness and Holiness: Readings in the Psychology/Theology of Mental Health Grand Rapids, Michigan: Baker Book House. pp. 136

19. Hyman H (1954) Interviewing in Social Research, Chicago: University of Chicago Press

20. Hyman H (1954) Interviewing in Social Research, Chicago: University of Chicago Press.

21. Hyman H (1954) Interviewing in Social Research, Chicago: University of Chicago Press.

22. Kaiser G (1982) Research in Criminal Justice: stocktaking of Criminological Research at Max-Planck-Institute for Foreign and International Penal Law after a Decade. Criminological Research Unit. Freiburg. 